\title{
Modernidad, globalización y derechos humanos: breves notas desde el pensamiento jurídico crítico latinoamericano ${ }^{1}$
}

\author{
Por Eduardo Carlos Rojas
}

\section{I.- Introducción}

El lugar de los derechos humanos en las sociedades latinoamericanas se encuentra enmarcado en un específico patrón de poder. Dentro del mismo encontramos al menos dos elementos principales: el colonialismo y el capitalismo financiero transnacional. El primero es partícipe de la construcción de la modernidad, el segundo lo es de la globalización colonial y capitalista. Creados a partir de este misma modernidad, es dable cuestionarse por la capacidad que guardan los derechos humanos dentro de sí para poder subvertir el orden que les ha dado la vida. En este sentido el presente escrito intenta hacer síntesis de algunas posturas afines entre sí para poder revelar a los derechos humanos por fuera del plexo normativo. Esto es, ubicarlos como, y antes que nada, una herramienta política cristalizada en el derecho.

Se realizará una breve introducción a ciertos aspectos del mundo moderno colonial, junto con algunas reflexiones en torno a su globalización en relación al derecho. Posteriormente se entroncará brevemente a los derechos humanos con esta dinámica globalizadora.

\section{II.- Modernidad colonial y globalización}

\section{A) Modernidad Colonial}

Una tradicional lectura de la modernidad entiende que la misma tiene su origen a causa de procesos propios europeos ${ }^{2}$. Presentando así la idea de ser la modernidad un

1 Hacemos referencia con el termino Pensamiento Jurídico Critico Latinoamericano, a una tradición de reflexión en torno al derecho nacida poco después de nacida la modernidad. En este sentido apuntaremos brevemente que tal tradición tiene como objeto al derecho latinoamericano en relación a una caracterización de su sociedad -la latinoamericana- en tanto que colonial. Siendo que dentro de sí se pueden encontrar reflexiones en torno a distintas esferas del derecho como ser: derechos humanos, derecho constitucional, sociología jurídica, filosofía del derecho, etc. La presente escueta aclaración se realiza a los fines de contextualizar el esbozo de mixtura de la Critica Jurídica con la tradición de pensamiento latinoamericano del último apartado, de donde esperamos poder encontrar con tiempo una Critica Jurídica Latinoamericana.

2 En este sentido podemos encontrar a modo de ejemplo: Jürgen Habermas, El discurso filosófico de la modernidad, Buenos Aires, Katz, 2008; Stephen Toulmin, Cosmópolis: el trasfondo de la modernidad, Trad. B. Moreno Carrillo, Barcelona, Península, 2001. 
fenómeno exclusivamente europeo en cuanto a su formación y en cuanto a su devenir, más no por tal razón imposible de ser apropiable por otras sociedades. Esta misma argumentación subsume dentro de sí la idea de ver al resto del mundo con la posibilidad (¿obligación?) de alcanzar el orden de la modernidad y desde esta posición poder realizar el juicio respecto de su desarrollo o subdesarrollo. Por otra parte la tradición de pensamiento latinoamericano ${ }^{3}$ específicamente también se ha dado a la tarea de pensar a la modernidad. Considerando como punto de partida a la realidad latinoamericana para la reflexión, ha arribado a conclusiones particulares respecto de problemáticas universales. En lo que sigue nos guiaremos en función de algunos de los autores que la componen para denotar una particular forma de entender a la modernidad ${ }^{4}$.

En este sentido diremos que el comienzo de la modernidad se encuentra en 1492 con la invención y conquista de América ${ }^{5}$. De este modo lo afirma Dussel, para quien la modernidad es un fenómeno europeo, pero uno constituido en una relación dialéctica con una alteridad no-europea que finalmente es su contenido. La modernidad aparece cuando Europa se autoafirma como "centro" de una Historia Mundo que ella inaugura; la "periferia" que rodea este centro es, consecuentemente, parte de esta auto-definición

Así, si 1492 es el momento del nacimiento de la modernidad como un concepto, el origen de un muy particular mito de violencia sacrificial, también marca el origen de un proceso de ocultamiento o no reconocimiento de lo no-europeo (Dussel, 2000:45).

Por tal motivo la primera definición que hemos esbozado de la modernidad es una que el autor argentino-mexicano tildará de eurocéntrica, provinciana y regional, toda vez que entiende a la sociedad europea como suficiente para gestar y desarrollar la modernidad, sin la necesidad de la participación de ninguna otra sociedad. En otras palabras el eurocentrismo radica en haber confundido la universalidad abstracta con la mundialidad concreta hegemonizada por Europa como "centro" (Idem: 45). De todos modos que la sociedad europea se crea la culminación de un proceso evolutivo puede no llegar a constituir una gran novedad, comparada con el hecho de que sea el resto de la población mundial la que se apropió también de esta idea, haciendo de esta visión provinciana una universal(Quijano, S/A: 212).

3 A tales efectos pueden consultarse: Carlos Altamirano, Historia de los intelectuales en América Latina, Buenos Aires, Katz, 2008-2010, dos tomos; Carlos Beorlegui, Historia del pensamiento filosófico latinoamericano. Una búsqueda incesante de la identidad, Bilbao, Universidad de Deusto, 2006; Eduardo Devés Valdés, El pensamiento latinoamericano del siglo XX. Entre la modernización y la identidad, Buenos Aires, 2000-2004, tres tomos; Carlos Piñeiro Iñíguez, Pensadores latinoamericanos del siglo XX: ideas, utopía y destino, Buenos Aires, Instituto Di Tella/Siglo XXI, 2006.

4 En lo esencial, nos centraremos en la relación existente entre modernidad y colonialidad o colonialismo. Términos estos ambos que si bien se inscriben en tradiciones de pensamiento no necesariamente similares, bien entienden los mismos puntos respecto de lo que traeremos al escrito.

5 En el sentido que lo plantea $\mathrm{O}$ 'Gorman Edmundo, La Invención de América, México, Fondo de Cultura Económica, 2006 
Este es el mito de la modernidad ${ }^{6}$ del cual nos habla Dussel. Su funcionalidad radica en ser precisamente la justificación de una violencia genocida a la par de la declamación de la emancipación como bandera universal. Proceso este que puede ser llevado a cabo mediante la negación de la periferia. Razón por la cual podemos establecer que a la par que existe un aspecto de libertad y emancipación en el discurso de la modernidad, también existe uno de negación. No acaso porque tal ultimo fenómeno sea coyunturalmente concomitante con el nacimiento de la modernidad, sino más bien porque es su condición de posibilidad, nos referimos a la Colonialidad.

Quijano nos explica que con la conquista de América se gesta un patrón de poder mundial que articula tres elementos: la colonialidad del poder, el capitalismo y el eurocentrismo. El eje central del primero será la creación del constructo de raza (Quijano, 2000: 342). Siendo que el mismo ha posibilitado la clasificación de la población a nivel mundial, asimilando características fenotípicas con cualidades del ser $^{7}$. Sobre el mismo se articulan las relaciones de explotación del capitalismo, siendo

6 El mito de la modernidad, genera a su vez la percepción de encontrarse un necesario vínculo histórico desde la antigua Grecia, hacia Roma, pasando posteriormente a la Europa occidental y luego al resto del mundo. En términos universales se trata del desplazamiento del Espíritu hegeliano y sus connotaciones para el resto de la humanidad no-europea. Contra este mito también se ha expresado Quijano al establecer que: "Lo que es curioso de ese argumento es que escamotea, primero, el hecho de que la parte realmente avanzada de ese mundo del Mediterráneo, antes de América, área por área de esa modernidad, era islamo-judaica. Segundo, que fue dentro de ese mundo que se mantuvo la herencia cultural greco-romana, las ciudades, el comercio, la agricultura comercial, la minería, la textilería, la filosofía, la historia, cuando la futura Europa Occidental estaba dominada por el feudalismo y su oscurantismo cultural. Tercero que, muy probablemente, la mercantilización de la fuerza de trabajo, la relación capital-salario, emergió, precisamente, en esa área y fue en su desarrollo que se expandió posteriormente hacia el norte de la futura Europa. Cuarto, que solamente a partir de la derrota del Islam y del posterior desplazamiento de la hegemonía sobre el mercado mundial al centro-norte de la futura Europa, gracias a América, comienza también a desplazarse el centro de la actividad cultural a esa nueva región". Aníbal Quijano, "Colonialidad del Poder, Eurocentrismo y América Latina”, en Edgardo Lander (comp.), La colonialidad del saber..., Op. Cit., p 213. En análisis más minucioso respecto del tópico puede encontrarse en Enrique Dussel, "Contexto de la Política Moderna” en su libro, Política de la liberación. Historia mundial y crítica, Madrid, Trotta, 2007, pp. $143-185$.

7 En palabras del propio Quijano: "La idea de raza es, con toda seguridad, el más eficaz instrumento de dominación social inventado en los últimos 500 años. Producida en el mero comienzo de la formación de América y del capitalismo, en el tránsito del siglo XV al XVI, en las centurias siguientes fue impuesta sobre toda la población del planeta como parte de la dominación colonial de Europa [...] De una parte: "Indio", "Negro", "Asiático" (antes "Amarillos" y "Aceitunados"), "Blanco" y "Mestizo". De la otra: "América", "Europa", "África", "Asia" y "Oceanía". Sobre ella se fundó el eurocentramiento del poder mundial capitalista y la consiguiente distribución mundial del trabajo y del intercambio. Y también sobre ella se trazaron las diferencias y distancias específicas en la respectiva configuración específica de poder, con sus cruciales implicaciones en el proceso de democratización de sociedades y Estados y de formación de Estados-nación modernos." Aníbal Quijano, “iQue tal raza!", en Zulma Palermo y Pablo Quintero (comps), Aníbal Quijano. Textos fundamentales, Buenos Aires, Del Signo 2014, p 96. 
que la gran mayoría de la población ahora clasificada como "india" o "negra", es mantenida en trabajo no asalariado en beneficio global del capital. En tanto que el eurocentrismo, se sitúa en el nivel de producción y reproducción del conocimiento, reflejando que la única forma valida de ser del conocimiento es aquella que se sigue del modo europeo, negando así la calidad de científico o conocimiento valido a los demás saberes de las culturas no-europeas.

En este sentido, la gestación de la modernidad trajo consigo la invención de múltiples principios organizacionales de la sociedad. Entonces, entiéndase que por ser el primer modo de organización globalizable (y de hecho globalizado), la modernidad no encuentra sus límites geográficos en la Europa medieval, sino que los supera hasta el límite geográfico del planeta mismo. Así vista, la reorganización de: las relaciones geo-políticas entre distintas culturas; las condiciones de producción del conocimiento; la organización política, social y económica; y la clasificación de la población a nivel mundial, son algunas de sus notas características. Todas ellas cambiaron la percepción que del mundo se tenía y generaron por consecuencia un nuevo horizonte de posibilidades y expectativas. El autor peruano nos ilustra al decir que:

[...] se trata de procesos que se inician con la conquista de América, de un nuevo patrón de poder mundial y de la integración de los pueblos de todo el mundo en ese proceso, de un entero y complejo sistema-mundo, es también imprescindible admitir que se trata de todo un periodo histórico. En otros términos, a partir de América un nuevo espacio tiempo se constituye, material y subjetivamente: eso es lo que mienta el concepto de modernidad (Quijano, 2000: 216).

Se reafirma entonces la participación de esa periferia negada, como necesaria en el nacimiento de la modernidad, en tanto que pocas veces mencionada, la Colonialidad es el aspecto constitutivo de tal modernidad junto con su desarrollo. Así, pareciera ser la concatenación de distintos hechos como lógica de una modernidad capitalista y no un específico patrón de poder que le permitió -a esta- su nacimiento y actual existencia. Puestas así las cosas, el nacimiento de la modernidad generó un trasfondo -colonial- con, al menos, dos características principales: ser su pilar de soporte y su aspecto más negado. Como mundo negado que es, el Mundo Colonial tiene una aplicación -recepción- distinta de los principios afirmados por la modernidad. Es por ello que a través de su estudio puede revelarse lo acotado -por no decir nulo- sobre la universalidad de los postulados que la modernidad proclamó precisamente como universales. De este modo Dussel nos avala al decir que:

8 El eurocentrismo hace parecer como naturales la experiencia social producida dentro de la Colonialidad del poder, imponiendo una única racionalidad. "Aplicada de manera específica -dice Quijano- a la experiencia histórica latinoamericana, la perspectiva eurocéntrica de conocimiento opera como un espejo que distorsiona lo que refleja. Es decir, la imagen que encontramos en ese espejo no es del todo quimérica, ya que poseemos tantos y tan importantes rasgos históricos europeos en tantos aspectos, materiales e intersubjetivos Pero, al mismo tiempo, somos tan profundamente distintos”. Aníbal Quijano, "Colonialidad del Poder, Eurocentrismo y América Latina”...Op. Cit., pp. 225-227. 
Este sentido de la relación entre la conquista de América y la formación de la Europa Moderna permite una nueva definición, una nueva visión global de la modernidad, que muestra no solo su lado emancipador sino también su costado destructivo y genocida (Dussel, 2001:68).

A este respecto se genera entonces una relación necesaria y conflictiva entre modernidad y colonialidad, toda vez que los explotados y dominados en el mundo colonial también se apropiaron del horizonte de libertad que aquella propugna. Se genera así un devenir traducible tanto en conflicto de intereses, como ambigüedad, dentro de la cual se inscribe la lucha por la democratización de la existencia social.

\section{B) Globalización y derecho colonial}

Hemos dicho hasta ahora que la inclusión de América en la escena mundial trajo aparejada la re-organización geopolítica del mundo hasta ese momento existente, dando la posibilidad de configuración de un patrón de poder con vocación mundial, como dice el autor peruano mismo:

Pero el "mundo" - si con ese término se implica la existencia social humana articulada en una específica totalidad histórica-, sea o no globalizable, no podría entenderse por fuera del hecho de que es un especifico patrón de poder lo que le otorga su carácter de "mundo" o de totalidad histórica específica, sin cuya condición cualquier idea de "globalización" seria simplemente inútil. De otro modo resultaría que las redes de comunicación, de información, de intercambio, etc., etc., existen y operan en una suerte de vacuum histórico (Quijano, 2001:S/P).

David Harvey ha propuesto entender que el proceso de acumulación originaria planteado por Marx, debería nominarse "acumulación por desposesión". Esto en relación a comprender que el mismo no es algo anterior y externo al capitalismo, sino continuo dentro del mismo. Así, nos dice que:

Una mirada más atenta de la descripción que hace Marx de la acumulación originaria revela un rango amplio de procesos. Estos incluyen la mercantilización y privatización de la tierra y la expulsión forzosa de las poblaciones campesinas; la conversión de diversas formas de derechos de propiedad -común, colectiva, estatal, etc.- en derechos de propiedad exclusivos; la supresión del derecho a los bienes comunes; la transformación de la fuerza de trabajo en mercancía y la supresión de formas de producción y consumo alternativas; los procesos coloniales, neocoloniales e imperiales de apropiación de activos, incluyendo los recursos naturales; la monetización de los intercambios y la recaudación de impuestos, particularmente de la tierra; el tráfico de esclavos; y la usura, la deuda pública y, finalmente, el sistema de crédito (Harvey, 2005:113).

La pertinencia del análisis de Harvey radica en considerar como procesos de acumulación por desposesión varias actividades que no solamente son aquellas denunciadas por Quijano y Dussel como partícipes durante el S. XVI de sustento para la configuración de la modernidad capitalista, sino a su vez procesos que de manera ininterrumpida han tenido lugar a lo largo de la historia de América Latina. Es decir 
que, es posible trazar un puente entre los procesos de acumulación por desposesión y los procesos coloniales de la modernidad. Lo que nos interesara sobre este tópico será su correlato con el derecho. Si bien esta dinámica entre procesos de expansión del capitalismo y colonialismo pueden encontrar justificación en el proceso histórico de consolidación de la modernidad capitalista, como es el caso de la Filosofía del Derecho de Hegel $^{9}$, nos centraremos en la producción jurídica en la fase actual del colonialismo ${ }^{1011}$. Nos referimos entonces a incluir dentro del análisis de la dinámica de la globalización de la modernidad colonial, al estado-nación. Consideramos la relevancia de la misma no acaso por considerar que el estado es el único productor del derecho $^{12}$, sino más bien por comprender que tales procesos son realizados con la intervención del estado (sea tanto por acción como por acción por omisión), pues:

como en el pasado, el poder del estado es usado frecuentemente para forzar estos procesos, incluso en contra de la voluntad popular. Como también sucedió en el pasado, estos procesos de desposesión están provocando amplia resistencia, de esto se trata el movimiento antiglobalización. La vuelta al dominio privado de derechos de propiedad común ganados a través de la lucha de clases del pasado (el derecho a una pensión estatal, al bienestar, o al sistema de salud nacional) ha sido una de las políticas de desposesión más egregias llevadas a cabo en nombre de la ortodoxia neoliberal (Harvey, 2005:115).

En esta misma línea podemos afirmar que "el imperialismo no puede sostenerse por mucho tiempo sin represión activa, o incluso tiranía interna” (Idem), donde tal represión demuestra que el achicamiento del estado solo lo es en algunas esferas que eran propias del "estado de bienestar". Contrario sensu, el estado interviene en salvaguarda de las necesidades de la expansión del capitalismo, sea a través del derecho, sea a través del uso del monopolio de la fuerza.

9 Hegel propone abiertamente el colonialismo como un mecanismo de resolución al problema del excedente de la producción. En este sentido encontramos los parágrafos 246 y 248:"246.- Por medio de su dialéctica la Sociedad Civil, sobre todo está determinada sociedad, es empujada más allá de sí para buscar fuera, en otros pueblos -que están atrasados respecto a los medios que ella posee con exceso, o con respecto a la industria- a los consumidores y, por lo tanto, los medios necesarios de su subsistencia" [...] "248.- La ampliación de ese enlace proporciona el medio de la colonización, a la cual -esporádica o sistemáticamente-, es empujada la sociedad civil adelantada, y con la que procura, en parte, el retorno al principio familiar a una fracción de la población en un nuevo territorio; y, en parte, procura para sí misma una nueva necesidad y un nuevo campo para la aplicación continuada del trabajo”. Georg Hegel, Filosofía del Derecho, Buenos Aires, Claridad, 1968, pp 206-208.

10 Tal como lo referencia Eugenio Zaffaroni, El derecho latinoamericano en la fase superior del colonialismo, Buenos Aires, Madres de Plaza de Mayo, 2015.

11 Si bien hasta el momento hemos trabajado la perspectiva de la Colonialidad del Poder, entendemos que la descripción que Zaffaroni hace del colonialismo es compatible con tal perspectiva en relación al nivel de análisis que aquí es esbozado.

12 Sería un contrasentido en este punto negar la existencia de un pluralismo jurídico desde abajo y emancipador 
Sassen da por sentado un proceso de globalización económica que tiene entre sus componentes principales a los sujetos transnacionales ${ }^{13}$, a los estados y a la producción normativa. De la dinámica de estos tres elementos encuentra que la capacidad de regulación de los estados ha variado significativamente, siendo que estamos asistiendo a la privatización de la capacidad normativa del estado. En este sentido, se está produciendo una desnacionalización, donde este término implica "un conjunto especifico de actividades que tienen lugar en los marcos institucionales nacionales, pero que se dirigen a cubrir las necesidades de programas económicos y políticos no nacionales o transnacionales y no las de los programas nacionales como ocurría antes" (Saskia Sassen, 2012:115). Mas, punto a considerar es que la producción normativa al estar siendo privatizada, está siendo realizada por órganos privados internacionales, hecho este que no escapa a la cotidianidad de los diarios latinoamericanos, cuando no mundiales.

Esta disminución de las capacidades del estado de producir derecho a causa de la autoridad normativa de organismos internacionales en función de la necesidad del capital transnacional, es un reflejo de las modificaciones en las relaciones sociales coloniales de producción. La necesidad del capital transnacional se centra tanto en una flexibilización del marco regulatorio del capital financiero, como así en el andamiaje normativo que regula el neo-extractivismo. Zaffaroni nos ilustra:

La proporción entre el capitalismo productivo y el capitalismo financiero se alteró, el capitalismo financiero se hipertrofió con relación al capitalismo productivo y el establishment se comió a la política, la controla. ¿Cómo la controla? Destruyendo Estados. [...] En otras regiones del mundo los debilita, y eso es lo que pasa en nuestra América Latina (Zaffaroni, 2016:114).

Derecho colonial por tanto es aquel que pervive en nuestras sociedades coloniales desde el comienzo de la modernidad misma. Atravesando las distintas etapas del capitalismo, nuestros estados fueron mutando en su relación de dependencia colonial, hecho que denota la modificación de su derecho en cada oportunidad. Asistimos a una nueva mutación, con una gran diferencia: los derechos humanos. Ante esta nueva fase -superior- del colonialismo, queda preguntarse: ¿Cuál es el rol de los derechos humanos?

\section{II.- Crítica jurídica y derechos humanos}

Afirmaremos que las cosas existen en dos órdenes, en el de la materia o el de la ideas, siendo que el primero es el que produce al segundo. En este sentido el derecho es un discurso, en tanto que las ideas solo pueden ser expresadas mediante el lenguaje. A su vez el lenguaje nos remite a la existencia de una ideología que lo dota de sentido en tanto que tal. En síntesis, el derecho es un discurso producto de una creación ideológica, o mejor aún, es ideología formalizada. Donde a su vez su finalidad es la

13 O sería más correcto decir al capital transnacional que se posa sobre estas personas jurídicas de existencia ideal transnacional al mero efecto de la circulación. 
reproducción de poder por parte del sector socialmente hegemónico que tiene la capacidad de establecerlo (Correas, 2003:63). Así arribamos a postular que el derecho es un discurso político. Por tal razón la crítica del discurso del derecho es un problema político y no uno científico.

Establecido fugazmente nuestro punto de partida, volvemos sobre la función de los derechos humanos. Mas por ser una parte de ese universo jurídico, los derechos humanos son también un discurso político, y muy probablemente el aspecto más político de todo el derecho ${ }^{14}$. Esto último debido a que la ideología que les dio su existencia es aquella que nace para enfrentarse la burguesía a la nobleza. Nacen como una herramienta jurídica en beneficio de aquella ${ }^{15}$. El pasaje de una argumentación iusnaturalista a una positivista encerrada en tratados internacionales puede entenderse de la mano de una modificación -expansión- del capitalismo. Es decir que la ideología que los fundamenta de una u otra manera es la misma, puesto que los derechos humanos prohíben el trabajo esclavo, pero no es conocida una carta internacional que prohíba la extracción de plusvalor. Es por esto que el jurista De la Torre de Lara establece:

La cultura constitucional y el planteamiento de los derechos humanos, si bien es cierto que poseen un importante potencial emancipador, también lo es que forman parte de nuevas formas de sometimiento y dominación, al ser producto de una matriz colonial/moderna que instituye e impone "el modo" a partir del cual se accede a los bienes exigibles para una vida digna; un orden jurídico/político impuesto y hostil hacia la mentalidad de la vida y el contexto político, económico, social y cultural donde se instaura (Arnulfo, 2006:151).

Como se deriva de los postulados que venimos trabajando y recalca el propio jurista mexicano, los derechos humanos en tanto enmarcados en una modernidad colonial, guardan también la posibilidad de una praxis emancipadora. Esto es posible toda vez que la modernidad permite la apropiación de sus postulados por parte de las mayorías excluidas, a través de una re-significación del discurso moderno. Es decir, mediante la lucha política por una verdadera democratización de la sociedad. Por vía de consecuencia:

Se trata de una verdadera e innegable contradicción en el sistema [los tratados de derechos humanos], provocada por el pánico que generó la barbarie entre los propios deficitarios de la melanina, producto de las contradicciones de su hegemonía precedente. La lucha mundial en el campo jurídico actual se entabla entre el poder

14 "Pero que los derechos humanos son ineluctablemente un discurso político, es algo que pertenece al mundo de los hechos; es un dato de la realidad, no un invento filosófico". Oscar Correas, "Los derechos humanos. Entre la historia y el mito", en Alejandro Rosillo (Coord.), Derechos humanos, pensamiento crítico y pluralismo jurídico, San Luis Potosí, UASLP, 2008, p 137.

15 En esta etapa la justificación de los derechos humanos es una que redunda en argumentaciones iusnaturalistas, por oposición a la gran mayoría de las argumentaciones presentes en las cuales los tratados internacionales de derechos humanos son parte del derecho positivo. Ambos son discursos políticos. 
transnacional, que quiere hacer que la frase de Marx pase a ser una fatal realidad e impedir cualquier redistribución de la renta, y quienes pretenden usar al derecho como herramienta redistributiva (Zaffaroni, 2015:82) ${ }^{16}$

Hace aproximadamente 40 años Oscar Correas escribía que si bien el derecho laboral no es la panacea de los obreros, tal como quieren hacerlo parecer los burgueses que lo controlan, por lo mismo que no es un fin en sí mismo, es un instrumento más para la lucha ${ }^{17}$. En la misma línea, la ideología colonial capitalista ha utilizado el discurso de los derechos humanos con miras a controlar la falta de democratización de las sociedades coloniales, es entonces cuando se abre la posibilidad de tomarlos como una herramienta de lucha política que propugne por una democratización de la existencia social, por una erradicación del colonialismo capitalista y por una realización del derecho humano al desarrollo desde las perspectivas y cosmovisiones que sean propias de cada pueblo ${ }^{18}$.

16 Zaffaroni hace referencia a la afirmación de Marx que comprendía que le derecho era solo un instrumento de la clase dominante.

17 Oscar Correas, Introducción a la crítica del derecho moderno, México, Triana, $3^{\circ}$ ed., 1993, p. 163.

18 "No hay tampoco "ética forense" posible, porque no hay justicia objetiva: lo que conviene al obrero enfurece al patrón. No hay términos medios. Por eso el ejercicio de la abogacía al servicio de los obreros es inmediatamente militancia política. Y por eso los abogados laboralistas suelen ser apetecible blanco de las organizaciones paramilitares”. Oscar Correas, Introducción a la crítica... Op. Cit., p. 164. En el mismo sentido pensamos 40 años después cual es el carácter de la defensa de los derechos humanos y cual es tristemente el escenario en que muchos abogados y activistas de derechos humanos desarrollan su praxis militante. 


\section{IV.- Bibliografía}

Altamirano, C. (2008). Historia de los intelectuales en América Latina, Buenos Aires, Katz.

Beorlegui, C. (2006). Historia del pensamiento filosófico latinoamericano. Una búsqueda incesante de la identidad, Bilbao, Universidad de Deusto.

CORREAS, O. (2003). Eficacia del derecho, efectividad de las normas y hegemonía política, México, UNAM: Ediciones Coyoacán.

(1993). Introducción a la crítica del derecho moderno, México, Triana, $3^{\circ} \mathrm{ed}$.

DE la TORRE DE LARA, O. (2006). "Ceguera ilustrada y cultura constitucional. Derechos humanos, territorialidad y sujetos de la historia”, en Revista de investigaciones juridicas, 2006, $\mathrm{N}^{\circ} 40$.

DEVÉS VALDÉS, E. (2000). El pensamiento latinoamericano del siglo XX. Entre la modernización y la identidad, Buenos Aires, 2000-2004, tres tomos.

Dussel, E. (2001). "Eurocentrismo y Modernidad (introducción a las lecturas de Frankfurt)", en Walter Mignolo (comp.) Capitalismo y geopolitica del conocimiento. El eurocentrismo y la filosofía de la liberación en el debate intelectual contemporáneo, Buenos Aires, Del Signo.

(2000). "Europa, modernidad y eurocentrismo", en Edgardo Lander (comp.), La Colonialidad del saber: eurocentrismo y ciencias sociales. Perspectivas latinoamericanas, Buenos Aires, Clacso.

(2007). "Contexto de la Política Moderna" en su libro, Política de la liberación. Historia mundial y crítica, Madrid, Trotta.

Habermas, J. (2008). El discurso filosófico de la modernidad, Buenos Aires, Katz, 2008.

HARVEY, D. (2005). "El nuevo imperialismo: acumulación por desposesión”, en Socialist register 2004 (enero 2005). Buenos Aires, CLACSO.

HeGEL, G. (1968). Filosofía del Derecho, Buenos Aires, Claridad.

O'Gorman E. (2006). La Invención de América, México, Fondo de Cultura Económica. 
PiÑEIRO IÑíGUEZ, C. (2006). Pensadores latinoamericanos del siglo XX: ideas, utopía y destino, Buenos Aires, Instituto Di Tella/Siglo XXI.

Quijano, A. (2000). "Colonialidad del Poder, Eurocentrismo y América Latina", en Edgardo Lander (comp.), La Colonialidad del saber: eurocentrismo y ciencias sociales. Perspectivas latinoamericanas, Buenos Aires, Clacso.

(2000). "Colonialidad y Clasificación Social", Festschrift For Immanuel Wallerstein, Journal of World Systems Research, vol. VI, No. 2, Fall/Winter.

Quijano. Textos fundamentales, Buenos Aires, Del Signo.

(2001) Colonialidad del Poder, Globalización y Democracia, en Tendencias Básicas de Nuestra Época: Globalización y Democracia. Instituto de Estudios Diplomáticos e Internacionales Pedro Gual. Caracas 2001.

SASSEN, S. (2003). "Desnacionalización de las políticas estatales y privatización de la producción de normas", en Teubner, Gunther, et al, Estado, soberanía y globalización, Bogota, Siglo del Hombre.

Toulmin, S. (2001). Cosmópolis: el trasfondo de la modernidad, Trad. B. Moreno Carrillo, Barcelona.

ZAFFARONI, E. (2015). El derecho latinoamericano en la fase superior del colonialismo, Buenos Aires, Madres de Plaza de Mayo.

(2016). América y su porvenir jurídico, Buenos Aires, Ediar. 
ENRIQUE D. (2000) "Europa, modernidad y eurocentrismo", en Edgardo Lander (comp.), La Colonialidad del saber: eurocentrismo y ciencias sociales. Perspectivas latinoamericanas, Buenos Aires, Clacso. 